\title{
МЕТОДИЧЕСКОЕ ОБОСНОВАНИЕ ПОВЫШЕНИЯ ВЫРАБОТКИ ЗАПАСОВ НЕФТИ МЕСТОРОЖДЕНИЙ, ОСЛОЖНЕННЫХ ТЕКТОНИЧЕСКИМИ НАРУШЕНИЯМИ
}

Стенькин Андрей Вениаминович', andrey.stenkin@lukoil.com

\author{
Котенев Юрий Алексеевич,3, \\ geokot@inbox.ru
}

Султанов Шамиль Ханифович ${ }^{2,3}$,

ssultanov@mail.ru

\author{
Уметбаев Виль Гайсович², \\ kafedragl@yandex.ru \\ 1 ТПП «Урайнефтегаз» $О О 0$ «ЛУКОЙЛ-Западная Сибирь», \\ Россия, 628285, ХМАО-Югра, Тюменская область, г. Урай, ул. Ленина, 116а. \\ 2 Уфимский государственный нефтяной технический университет, \\ Россия, 450062, Республика Башкортостан, г. Уфа, ул. Космонавтов, 1 \\ ${ }^{3}$ Институт стратегических исследований республики Башкортостан, \\ Россия, 450008, Республика Башкортостан, г. Уфа, ул. Кирова, 15.
}

Актуальность. Нефтегазовые залежи месторождений Шаимского района осложнены разнопорядковыми тектоническими нарушениями. В статье рассмотрено влияние тектонических нарушений на разработку залежей и выработку запасов нефти из них. Объектом исследования являются продуктивные пласты юрских отложений месторождения Шаимского нефтегазоносного района, характеризующиеся высокой степенью неоднородности и низкими значениями фильтрационно-емкостных свойств, осложнёнными тектоническими нарушениями. Недостижение проектных показателей выработки запасов нефти для подобных месторождений требует проведения детального мониторинга разработки с учетом ключевых геологических характеристик и последующего регулирования и совершенствования системы разработки. Методический подход к совершенствованию системы разработки месторождений, осложненных тектоническими нарушениями, должен включать критический анализ первичной геолого-геофизической и промысловой информации, анализ основных показателей разработки, характеризующих выработку запаСов нефти.

Цель работы: определение причин неравномерности выработки запасов по площади и разрезу продуктивных пластов, изучение влияния тектонических разломов различного порядка на эффективность реализуемой системы разработки, в том числе и на систему заводнения продуктивных пластов

Методы исследования: геолого-гидродинамическое моделирование разработки, геолого-промысловый анализ разработки, анализ результатов интерпретации гидродинамических исследований скважин, сопоставительный анализ фильтрационно-емкостных свойств пласта, полученных различными методами исследований. Анализ эффективности системы разработки проводился с использованием косвенных методов математической статистики, подкрепленных прямыми методами - трассерными исследованиями скважин.

Результаты. На примере Новомостовского нефтяного месторождения выделены гидродинамически обособленные участки с высокими значениями подвижных остаточных запасов, ограниченных тектоническими нарушениями, для которых предложены геолого-технические мероприятия и технологии, направленные на повышение выработки запасов нефти. По результатам проведенных исследований предложено методическое обоснование оперативного регулирования и мониторинга разработки пластов, осложненных тектоническими нарушениями.

\section{Ключевые слова:}

Месторождения Шаимского нефтегазоносного района, тектоническое нарушение

гидродинамическая взаимосвязь между скважинами, выработка запасов нефти, Новомостовское месторождение.

В последние два десятилетия в общемировых геологических запасах нефти и газа всё в большей степени начинают преобладать неантиклинальные ловушки углеводородов (УВ), среди которых значительное место принадлежит комплексным структурно-тектоническим, литолого-тектоническим и тектонически экранированным ловушкам [1-4]. Тектонические нарушения оказывают влияние на характер площадного распределения нефтегазоносности. Выявленные тектонические нарушения могут являться флюидоупорами, а их совокупность может сформировать диа- гональную систему разломов, вследствие чего вдоль плоскостей флюидоупоров происходит изменение уровня водонефтяного контакта (ВНК). В этой связи надёжное картирование дизъюнктивных дислокаций при построении детальных геологических моделей месторождений становится необходимым условием их успешной разведки и дальнейшего проектирования систем разработки и эксплуатации продуктивных залежей $[5,6]$.

Для месторождений Шаимского нефтегазоносного района (НГР) вопрос изучения и уточнения геоло- 
гического строения, в том числе распространения тектонических нарушений, является актуальным, особенно для месторождений со сформированной системой разработки. Наряду с широко развитыми разрывными нарушениями высокой амплитуды, для которых основным и достаточным признаком является разрыв и смещение продуктивных пластов по сместителю, важно выделять и картировать малоамплитудные нарушения, имеющие амплитуду смещения на грани разрешенности временного сейсмического разреза. Малоамплитудные смещения пластов, образующие в плане линейные аномалии, в существенной степени могут влиять на выработку запасов нефти. Это актуально и для месторождений Шаимского НГР при выделении и трассировании тектонических нарушений по отражающим горизонтам, стратифицируемым с кровлями продуктивных пластов верхней подсвиты тюменской свиты $Ю_{2}-Ю_{7}$. В границах только одного, среднего по запасам, месторождения данного НГР выделяются разломы ступенчатые и веерного строения [7-16].

Как уже отмечалось, сложное геологическое строение оказывает существенное влияние на величину отбора нефти месторождений, на которых запроектированный для бурения фонд скважин уже реализован [17-20]. В то же время по результатам эксплуатации скважин формируется представление об эффективности системы разработки и размещении скважин в условиях сильной тектонической деструкции продуктивных пластов [21-32].

Показательным примером влияния разломной тектоники на эффективность разработки для Шаимского НГР является Новомостовское месторож- дение, продуктивные пласты которого осложнены системой тектонических нарушений. При построении геологической модели продуктивных пластов $Ю_{2}-Ю_{7}$ было выделено 63 отдельных сегмента тектонических нарушений, при площади нефтеносности месторождения 7800 тыс. м² (рис. 1).

При проектировании Новомостовского месторождения, ввиду недостаточного представления 0 геологическом строении месторождения, в том числе о выдержанности пластов коллекторов $Ю_{2}-Ю_{6}$, заложении дизъюнктивных нарушений без смещения и с малой амплитудой смещения, была реализована площадная обращенная девятиточечная система разработки. Следует отметить, что с 2006 г. обзор проектных решений месторождений Шаимского и Красноленинского районов (Ем-Еговскомое, Кислорское, Ловинское, Сыморьяхское) свидетельствует о том, что на данных месторождения разработка продуктивных пластов тюменской свиты также осуществляется площадной обращенной девятиточечной системой с традиционным заводнением. Вышеуказанные месторождения, так же как и Новомостовское, с продуктивными пластами тюменской свиты имеют близкие геолого-геофизические параметры и характеризуются как высокорасчлененные, низкопроницаемые и прерывистые с вязкостью нефти 0,4-1,8 мПа.с. Залежи нефти месторождений характеризуются неравномерной выработкой запасов нефти по площади.

Фильтрационно-емкостные свойства (ФЕС) продуктивных пластов Новомостовского месторождения характеризуются низкой проницаемостью и высокой расчлененностью как по верти-

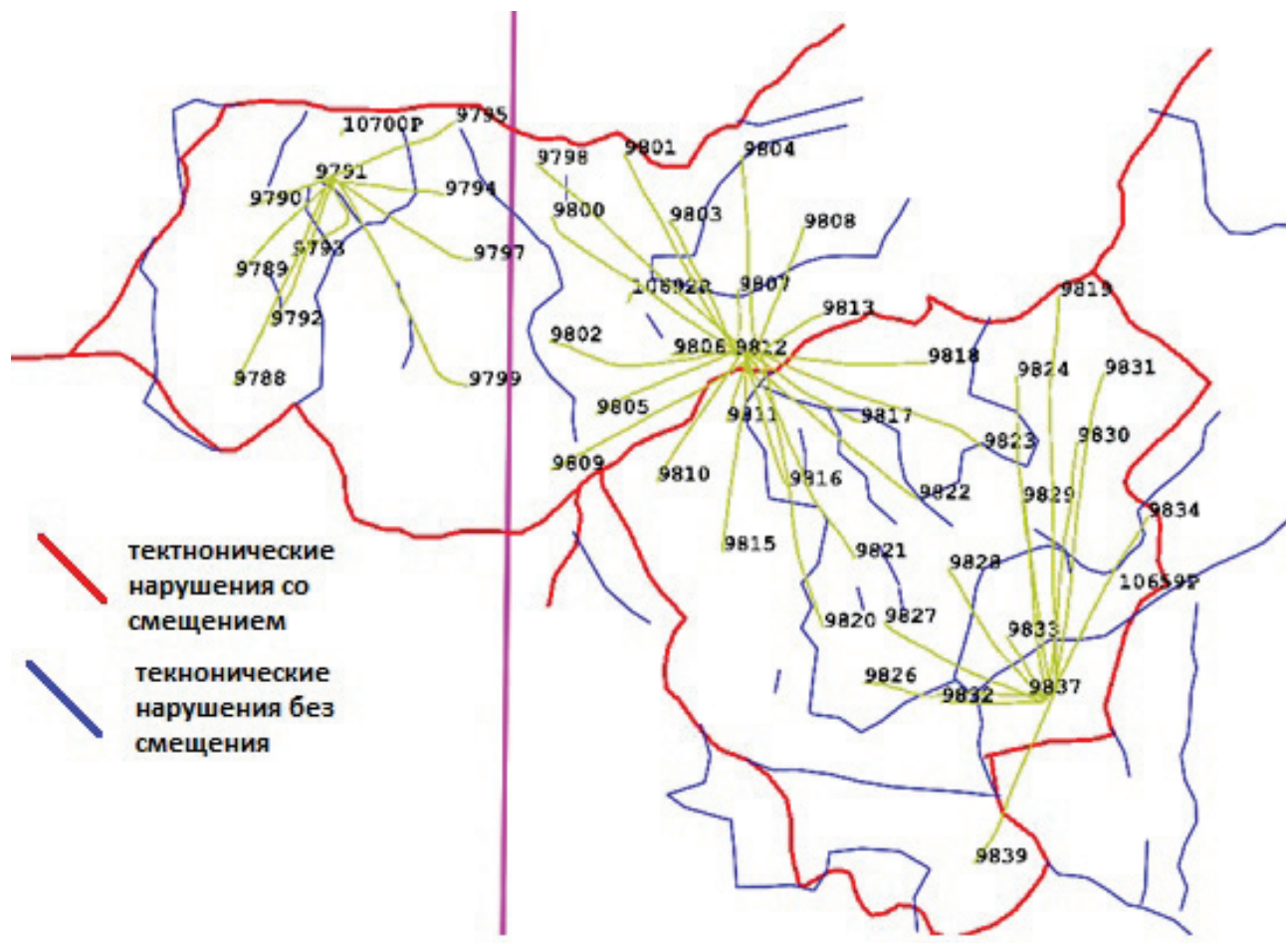

Рис. 1. Схема расположения разломов, выделенных в тюменской свите Новомостовского месторождения

Fig. 1. Scheme of the fault location of the Novomostovskoe oilfield in the Tyumen suite 
кальному разрезу, так и по латерали, тем самым усложняя процесс разработки и подбор геологотехнических мероприятий, направленных на увеличение нефтеотдачи пластов. Фактором, осложняющим прогнозирование добычи углеводородов, является значительный разброс в значениях основных параметров, характеризующих фильтрационно-емкостные свойства пласта: пористость и проницаемость. Проницаемость, определенная различными методами - керн, гидродинамические исследования скважин (ГДИС) и по данным геофизических исследований скважин (ГИС), имеет существенную разницу в определенных интервалах продуктивных пластов Новомостовского месторождения. Так, например, значительное расхождение (в три и более раза) обнаружено в 32 \% случаев. Особенно существенна разница показателей

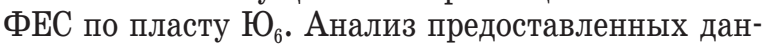
ных по ГИС, ГДИС и лабораторным исследованиям керна показал, что по скважинам с высоким расхождением значений рекомендуется переинтерпретация результатов исследований.

Геолого-промысловый анализ разработки и анализ выработки запасов нефти Новомостовского месторождения свидетельствуют о недостаточной эффективности разработки продуктивных пластов. Отмечаются опережающие темпы обводнения, объясняемые, вероятнее всего, наличием сети выявленных тектонических нарушений, являющихся каналами фильтрации и связывающих области дренирования скважин как с водонасыщенной частью пласта (водонасыщенные линзы присутствуют во всех пластах), так и с законтурной зоной. Характер выработки запасов нефти по площади месторождения также свидетельствует о наличии слабодренируемых участков. Около $69 \%$ нефтенасыщенной площади пласта $Ю_{6}$ занимают зоны с коэффициентом выработки ниже $18 \%$, cpeди которых более всего распространены по площади нефтенасыщенные толщины от 4 до 8 м, здесь на них приходится около 37 \% площади. Достаточно широко распространены по площади зоны с нефтенасыщенной толщиной от 8 до $12 \mathrm{M}$, где коэффициент выработки также в основном не превышает $21 \%$. На зоны с выработкой более $40 \%$ в целом по пласту приходится менее $6 \%$ общей площади нефтенасыщенных толщин.

В разрезе продуктивного пласта $Ю_{6}$ отмечено, что начальные подвижные запасы сосредоточены в основном в центральной его части, где также выделяется более интенсивная выработка. Доля извлечённых запасов нефти достигает $28 \%$, составляя в среднем $13 \%$.

Характер распределения основных технологических показателей разработки (удельных остаточных запасов, текущего пластового давления, обводненности) показывает высокую вариацию в пределах отдельных участков. Сопоставление указанных карт с картой расположения тектонических нарушений свидетельствует о видимой их корреляции.
Влияние тектонических разломов на выработку запасов нефти и оценка эффективности системы поддержания пластового давления, в том числе предположение о фильтрации пластового флюида через дизъюнктивные нарушения [17, 28-30], возможны и по анализу и сопоставлению ряда временных данных. К такой информации и данным можно отнести карты остаточных запасов нефти, изобар и разломов и их сопоставление, а также результаты анализа гидродинамических и трассерных исследований, статистических временных рядов «добыча-закачка», «добыча-добыча».

Совместный анализ карт изобар, разработки и остаточных запасов нефти по пластам Новомостовского месторождения показал, что отдельные зоны пластов характеризуются значительным перепадом пластового давления при больших объемах закачки рабочего агента с целью поддержания пластового давления (рис. 2).

Анализ основных показателей разработки свидетельствует о том, что текущий коэффициент использования запасов имеет низкие значения по пластам и эксплуатационные объекты разрабатываются неравномерно, при высокой обводненности продукции и снижении дебитов и пластового давления. Наблюдается рост пластового давления на участках, оконтуренных разрывными нарушениями при закачке рабочего агента, при этом дебиты нефти скважин низкие и с высокой долей воды в объеме добываемой продукции. Перераспределение давления не происходит, возможно, из-за слабопроницаемых тектонических нарушений.

С целью определения гидродинамического взаимодействия между нагнетательными и добывающими скважинами выполнен статистический (регрессионный) анализ по временным рядам «закачка воды - отбор жидкости». Анализ показал, что имеются скважины с отсутствием взаимосвязи. Это обусловлено особенностями геологического строения - наличием разломов (рис. 3 , таблица).

таблица. Коэффициент корреляции по скважинам на выделенном участке № 1

Table. $\quad$ Correlation coefficient of production wells on the allocated site № 1

\begin{tabular}{|c|c|c|c|}
\hline \multicolumn{2}{|c|}{$\begin{array}{c}\text { Скважины } \\
\text { Wells }\end{array}$} & $\begin{array}{c}\text { Разрабатываемый пласт } \\
\text { Developed layer }\end{array}$ & $\begin{array}{c}\text { Коэффициент корреляции } \\
\text { Correlation coefficient }\end{array}$ \\
\hline 9823 & 9829 & $Ю_{6}$ & 0,024 \\
\hline 9834 & 9829 & $\mathrm{Ю}_{6}$ & 0,001 \\
\hline 9818 & 9831 & $\mathrm{Ю}_{2}$ & 0,784 \\
\hline 9818 & 9831 & $\mathrm{Ю}_{6}$ & 0,179 \\
\hline 9823 & 9824 & $\mathrm{Ю}_{4}$ & 0,003 \\
\hline 9823 & 9824 & $\mathrm{Ю}_{2}$ & 0,054 \\
\hline
\end{tabular}

Для оценки достоверности полученных результатов корреляционные зависимости сравнивались с результатами трассерных исследований. По результатам данного сопоставления получена высокая сходимость. Оценка гидродинамической связи между скважинами трассерными исследованиями 


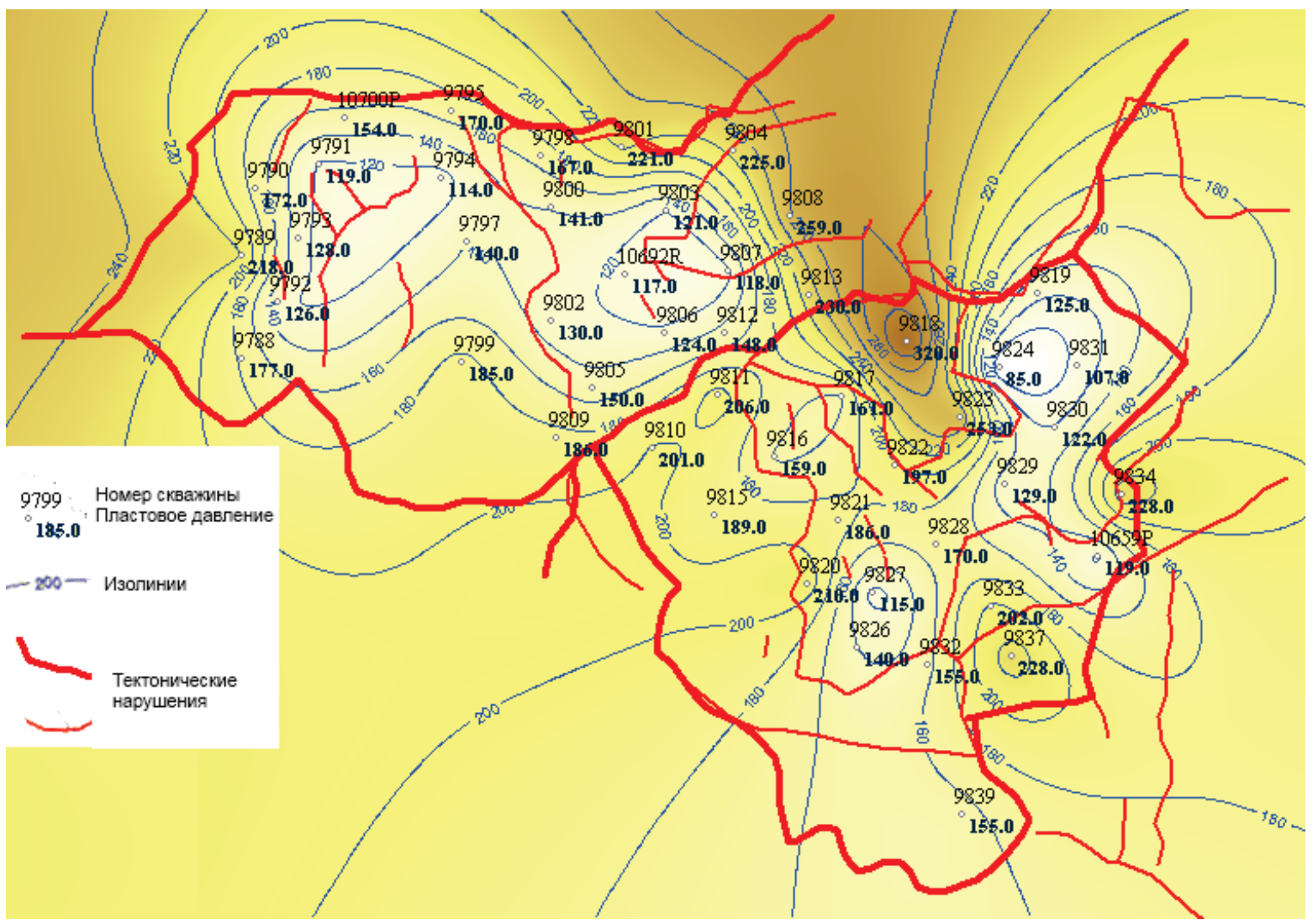

Pис. 2. Карта изобар с границами разнопорядковых тектонических нарушений Новомостовского месторождения

Fig. 2. Isobars map with the boundaries of different-order tectonic disturbances of the Novomostovskoe oilfield

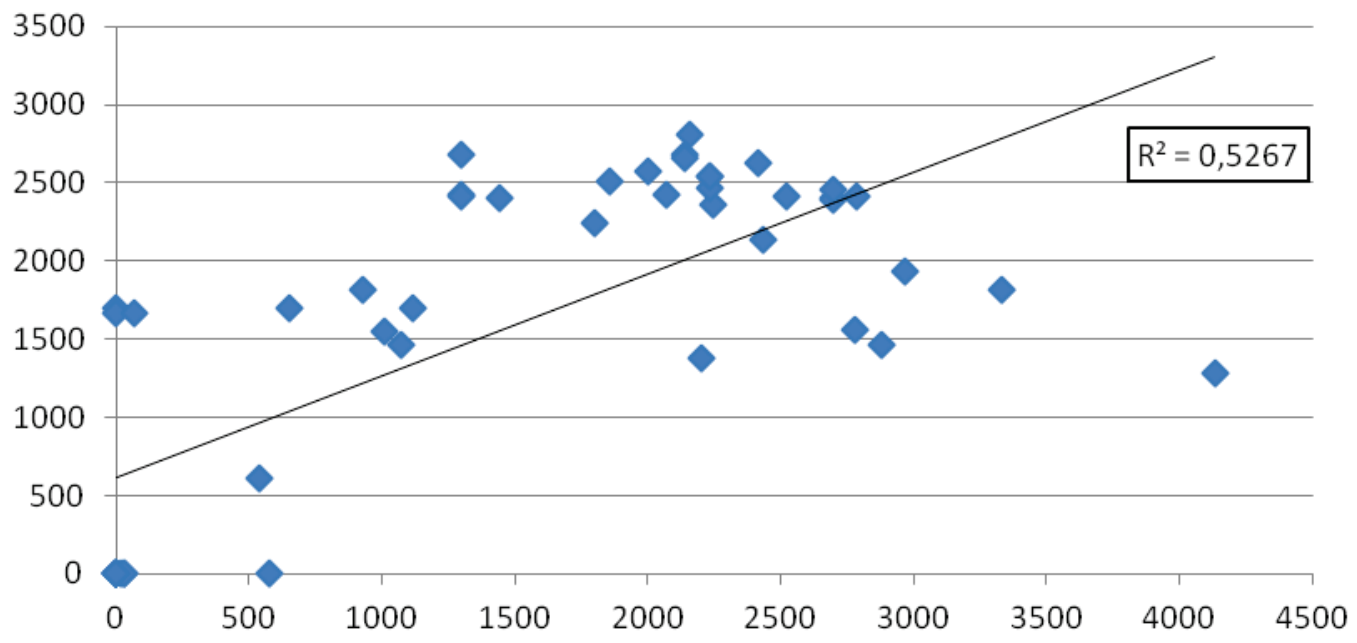

Рис. 3. График сопоставления показателей добычи жидкости и закачки воды нагнетательной скважины 9810 и добывающей скважины 9805, разрабатывающих пласт $Ю_{6}$

Fig. 3. Graph comparing fluid production and water injection through the injection well 9834 and the production well 9829 of the $U_{6}$

выполнена по ограниченному их количеству. И в связи с тем, что имеется подтверждение данных статистического анализа трассерными исследованиями, результаты взаимовлияния «добыча-закачка» и «добыча-добыча», полученные математическими расчетами, были приняты для пар скважин всего продуктивного пласта [4-6].
Составление карт остаточных запасов нефти, изобар, тектонических нарушений и коэффициентов корреляции позволило выделить участки, которые можно охарактеризовать как условно гидродинамически локализованные (рис. 2). На карте отчетливо выделяются перепады значения пластового давления, ограниченные тектоническими раз- 
ломами, что в свою очередь свидетельствует о слабой проницаемости отдельных тектонических нарушений.

Выполненный по выделенным участкам геолого-промысловый анализ разработки свидетельствует о том, что по ним имеется потенциал повышения эффективности выработки запасов нефти путем совершенствования системы заводнения. Это приведет к постепенному восполнению энергетического состояния участков, планированию геолого-технических мероприятий (ГТМ) [5].

В условиях неопределенности границ гидродинамически связанного пласта рекомендуется проведение гидропрослушивания пласта, в том числе по причине наличия в непосредственной близости тектонического нарушения (разлома). При наличии слабой гидродинамической связи или полного ее отсутствия между скважинами могут быть предложены ГТМ, направленные на увеличение проницаемости пласта, например гидравлический разрыв пласта (ГРП). Проведение ГРП актуально для условий Новомоствоского месторождения, эксплуатационные объекты которого характеризуются:

- высокой расчлененностью $(0,28-0,30)$ по пластам $Ю_{3}, Ю_{4}, Ю_{6}$;

- высокой неоднородностью как по разрезу, так и по латерали, в связи с линзовидным строением коллектора;
- низкой проницаемостью коллектора;

- зонами замещения коллектора в пластах $Ю_{2}$ и $Ю_{5}$.

Для месторождений, залежи которых представлены неоднородным и низкопроницаемым коллектором, осложненных тектоническими нарушениями различного порядка, в условиях доступной информации и данных, рекомендуется методическое обоснование для выполнения оперативного регулирования и мониторинга разработки продуктивных пластов (рис. 4).

\section{Выводы}

Эффективная разработка месторождений с трудноизвлекаемыми запасами нефти требует оперативного регулирования разработки месторождений. В случае месторождений с залежами нефти, осложненными большим количеством тектонических нарушений, в том числе имеющих значительную амплитуду смещения продуктивных пластов, которые в свою очередь являются сильнорасчлененными и слабопроницаемыми, необходимо методическое сопровождение, позволяющее получить достоверное представление о гидродинамической связи коллектора как по разрезу, так и по площади и включающее:

- сравнительный анализ показателей фильтрационно-емкостных свойств пласта, определенных различными методами;

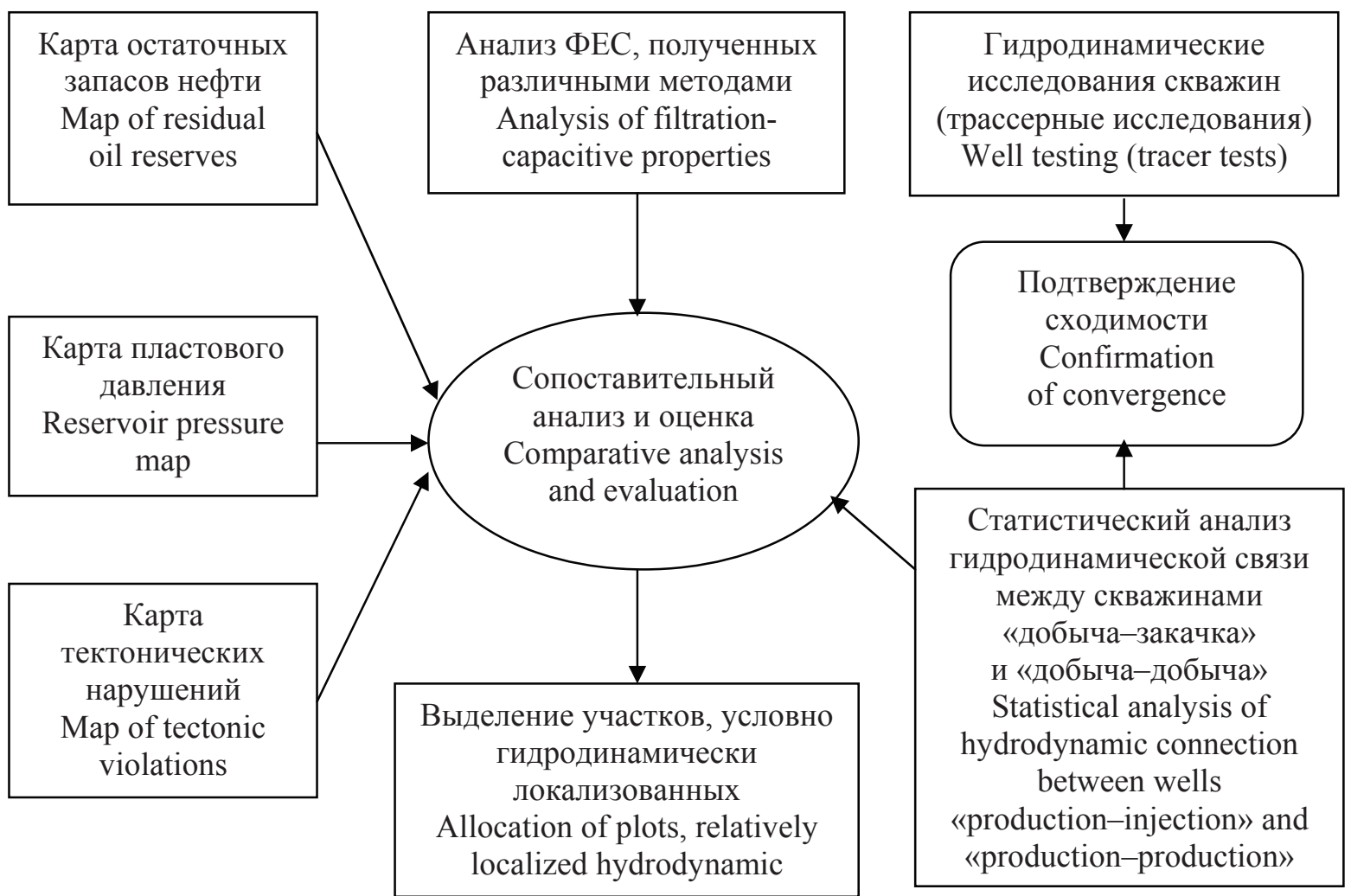

Рис. 4. Схема выделения участков, гидродинамически локализованных тектоническими нарушениями

Fig. 4. Scheme of allocation of the areas hydrodynamically localized by tectonic disturbances 
- анализ распределения остаточных запасов нефти, пластового давления в границах зон с тектоническими нарушениями;

- анализ и сопоставление гидродинамических методов исследований скважин (трассерных ис-

\section{СПИСОК ЛИТЕРАТУРЫ}

1. Особенности разработки залежей нефти, осложнённых тектоническими нарушениями / Ф.С. Салимов, А.Н. Лесной, Ю.А. Котенев, Д.Ю. Чудинова // Научно-технический журнал «Нефтегазовое дело». - 2016. - Т. 14. - № 1. - С. 42-48.

2. Особенности распределения физических свойств нефти в пластах Ватьеганского нефтяного месторождения / Л.Р. Фазылова, Ю.А. Котенев, Д.Ю. Чудинова, А.С. Валеев, М.Р. Дулкарнаев // Сборник научных трудов 43-й Международной научнотехнической конференции молодых ученых, аспирантов и студентов, посвященной 60 -летию филиала УГНТУ в г. Октябрьском. - Октябрьский, 2016. - С. 263-267.

3. Проблемы интенсификации добычи нефти в низкопродуктивных пластах сложного геологического строения месторождений Красноленинского свода Западной Сибири / О.Г. Зацепин, А.В. Стенькин, В.В. Икс, Ю.А. Котенев, Д.Ю. Чудинова // Сборник научных трудов 43-й Международной научно-технической конференции молодых ученых, аспирантов и студентов, посвященной 60-летию филиала УГНТУ в г. Октябрьском. - Октябрьский, 2016. - С. 166-170.

4. Методические основы планирования и организации интенсивных систем заводнения (на примере пластов Ватьеганского и Тевлинско-Русскинского месторождений) / А.С. Валеев, М.Р. Дулкарнаев, Ю.А. Котенев, Ш.Х. Султанов, Л.С. Бриллиант, Д.Ю. Чудинова // НТЖ «Экспозиция Нефть Газ». 2016. - № 3 (49). - C. $38-44$.

5. Геоинформационная стратегия разработки месторождений с трудноизвлекаемыми запасами нефти / Ш.Х. Султанов, Ю.А. Котенев, В.Е. Андреев, А.П. Стабинскас, И.В. Грехов // Георесурсы. - 2012. - № 3 (45). - С. 40-43.

6. Оптимизация системы заводнения в терригенных и карбонатных коллекторах / В.Е. Андреев, Д.Ю. Чудинова, А.П. Чижов, А.В. Чибисов // Научно-технический журнал «Проблемы сбора, подготовки и транспорта нефти и нефтепродуктов». 2016. - Вып. 4 (106). - С. 42-53.

7. Стратиграфия и палеогеография мезозойско-кайнозойского осадочного чехла Шаимского нефтегазоносного района (Западная Сибирь) / Э.О. Амон, В.П. Алексеев, А.Ф. Глебов, В.А. Савенко, Ю.Н. Федоров / под ред. В.П. Алексеева. - Екатеринбург: Изд-во УГГУ, 2010. - 257 с.

8. Палеофациальный анализ отложений тюменской свиты Красноленинского месторождения / С.Л. Белоусов, О.А. Хурамшина, С.В. Шабакова, Е.В. Чернова // Научно-технический вестник ОАО «НК «РОСНЕФТЬ» - - 2014. - № 3. - С. 8-12.

9. Бабин Е.А., Белозерова М.А., Ляпин А.В. Структурно-тектонические и сейсмодинамические особенности отложений тюменской свиты на примере месторождений ТПП «Урайнефтегаз» // Пути реализации нефтегазового и рудного потенциала XMA0-Югры: XVII науч.-практ. конф. - Ханты-Мансийск, 2013. - C. $152-159$.

10. Калгин В.П. Использование данных сейсморазведки для уточнения геологического строения тюменской свиты Красноленинского месторождения // Наука и ТЭК. - 2012. - № 4. - С. 25-26.

11. Перспективы нефтегазоносности отложений верхнетюменской подсвиты лицензионного участка Сургутский 7 / И.О. Быкова, С.Н. Шулико, А.А. Горячев, А.А. Вилисов, А.В. Коперчак // Пути реализации нефтегазового и рудного потенциала XMA0-Югры: XIV науч.-практ. конф. - Ханты-Мансийск, 2011. - C 350-359. следований) с результатами статистической обработки данных по межскважинной корреляции «добыча-закачка» и «добыча-добыча»;

- выделение участков и разработка мероприятий, направленных на повышение нефтеизвлечения.

12. Иванов И.В. Метод улучшения связанности коллекторов тюменской свиты месторождений Шаимского района при построении геологической модели на основе поинтервальной интерпретации ГИС // Пути реализации нефтегазового и рудного потенциала XMA0-Югры: XIV науч.-практ. конф. - Ханты-Мансийск, 2011. - С. 230-237.

13. Кузьмин Ю.А., Иванова Н.А., Хайновская Я.А. Влияние эпигенетических процессов на фильтрационно-емкостные свойства пород-коллекторов тюменской свиты Шаимского НГР // Пути реализации нефтегазового и рудного потенциала XMA0-Югры: XIV науч.-практ. конф. - Ханты-Мансийск, 2011. - C. 281-286.

14. Кузьмин Ю.А., Осипенко А.С. Мониторинг геологических моделей залежей тюменской свиты в процессе их доразведки и промышленности эксплуатации (на примере пласта $\mathrm{T}_{1}$ Славинского и Западно-Славинского месторождений // Пути реализации нефтегазового и рудного потенциала XMA0-Югры: XIV науч.-практ. конф. - Ханты-Мансийск, 2011. - С. 326-332.

15. Петрофизическая модель фильтрационно-емкостных свойств продуктивных отложений тюменской свиты Шаимского района / А.В. Мальшаков, В.А. Ефимов, Ю.А. Кузьмин, В.В. Борщев // Пути реализации нефтегазового потенциала XMA0: III науч.практ. конф. - Ханты-Мансийск, 2000. - С. 323-333.

16. История формирования отложений тюменской свиты Шаимского нефтегазоносного района / В.П. Алексеев, Ю.Н. Федоров, С.С. Газалеев, В.И. Русский, Л.И. Свечников, А.Ф. Хакимов // Геология угольных месторождений. - Екатеринбург: Изд-во УГГУ, 2004. - Вып. 14. - С. 130-139.

17. Методические аспекты исследования продуктивных отложений тюменской свиты Южно-Конитлорского месторождения по материалам сейсмической съемки 3D / И.Н. Керусов, П.Н. Страхов, И.Э. Керусова, Н.П. Нестеренко, Д.Е. Мирошниченко, А.А. Потрясов, К.Г. Скачек, М.В. Мордвинцев, Д.Н. Крылов, В.В. Черняева // Пути реализации нефтегазового потенциала XMA0: VII науч.-практ. конф. - Ханты-Мансийск, 2004. - С. 86-93.

18. Алексеев В.П., Газалеев С.С., Свечников Л.И. Строение и корреляция отложений тюменской свиты // Пути реализации нефтегазового потенциала XMA0: VIII науч.-практ. конф. Ханты-Мансийск, 2005. - С. 346-352.

19. Быкова И.О., Шулико С.Н., Быков А.В. Моделирование колекторских свойств тюменской свиты на примере месторождений Юганского Приобья // Пути реализации нефтегазового и рудного потенциала XMA0-Югры: XI науч.-практ. конф. Ханты-Мансийск, 2008. - С. 139-144.

20. Ошняков И.О. Уточнение петрофизической модели тюменской свиты Красноленинского месторождения // Наука и ТЭК. 2012 апрель. - № 4. - С. 43-44.

21. Mining disturbance effect and mining arrangements analysis of near-fault mining in high tectonic stress region / H.G. Ji, H.S. Ma, J.A. Wang, Y.H. Zhang, H. Cao // Safety Science. - April 2012. - V. 50. - Iss. 4. - P. 645-651.

22. Pinxian W., Qianyu Li, Chun-Feng Li. Ch. 3. Tectonic Framework and Magmatism // Developments in Marine Geology. - 2014. V. 6. - P. 81-84.

23. Kontorovich V.A. The Meso-Cenozoic tectonics and petroleum potential of West Siberia // Russian Geology and Geophysics. - April 2009. - V. 50. - Iss. 4. - P. 350-352.

24. Tertiary and Quaternary tectonic faulting in southernmost Illinois / W.J. Nelson, F.B. Denny, J.A. Devera, L.R. Follmer, J.M. Ma- 
sters // Engineering Geology. - 15 July 1997. - V. 46. Iss. $3-4$. - P. 240-242.

25. Dayal A.M. Basin Structure, Tectonics, and Stratigraphy // Shale Gas, Exploration and Environmental and Economic Impacts. 2017. - V. 2. - P. 57-59.

26. The structural elements and tectonics of the Lake Van basin (Eastern Anatolia) from multi-channel seismic reflection profiles / M. Toker, A.M. Celal Sengorc, F.D. Demirel Schluter, E. Demirbag, D. Cukur, C. Imren, F. Niessen // Journal of African Earth Sciences. - May 2017. - V. 129. - P. 170-172.

27. Determination of dynamic reserves of fractured horizontal wells in tight oil reservoirs by multi-region material balance method / Y. Wei, Q. Ran, Li Ran, J. Yuan, J. Dong // Petroleum Exploration and Development. - June 2016. - V. 43. - Iss. 3. P. 493-495.

28. Clancya S.A., Worralla F., Daviesb R.J., Gluyasa J.G. An assessment of the footprint and carrying capacity of oil and gas well sites: the implications for limiting hydrocarbon reserves // Science of The Total Environment. - 2017. - V. 618. - P. 586-594.
29. Abdus Satter A., Iqbal G.M. Conventional and unconventional petroleum reserves - definitions and world outlook // Reservoir Engineering. The Fundamentals, Simulation, and Management of Conventional and Unconventional Recoveries. - 2016. P. $436-437$.

30. One-dimensional modeling of a recent Ganga avulsion: assessing the potential effect of tectonic subsidence on a large river / N. Gupta, M.G. Kleinhansb, E.A. Addinkb, P.M. Atkinsona, P.A. Carlinga // Geomorphology. - 15 May 2014. - V. 213. P. 25-29.

31. McCall G.J.H. Tectonics // Reference Module in Earth Systems and Environmental Sciences. - 2013. - V. 227. - P. 320-322.

32. Somnath D., Boseb S., Dasc K. Tectonic evolution of the Eastern Ghats Belt // Precambrian Research. - April 2013. - V. 227. P. 250-252.

\section{Информация об авторах}

Стенькин A.B., заместитель генерального директора по разработке месторождений, главный геолог ТПП «Урайнефтегаз» 000 «ЛУКОЙЛ-Западная Сибирь», Россия, 628285, ХМАО-Югра.

Котенев Ю.А., доктор технических наук, профессор, заведующий кафедрой геологии и разведки нефтяных и газовых месторождений Уфимского государственного нефтяного технического университета; заведующий лабораторией «Технология воздействия на пласт» Института стратегических исследований республики Башкортостан.

Султанов Ш.X., доктор технических наук, профессор, заведующий кафедрой геологии и разведки нефтяных и газовых месторождений Уфимского государственного нефтяного технического университета; заведующий лабораторией «Математическое моделирование процессов нефтегазоизвлечения» Института стратегических исследований республики Башкортостан.

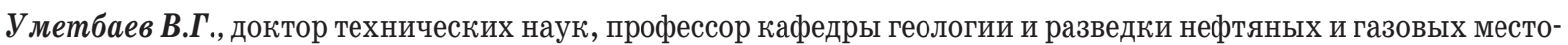
рождений Уфимского государственного нефтяного технического университета. 
UDC 622.276

\section{METHODICAL SUBSTANTIATION OF INCREASING PRODUCTION OF OIL RESERVES ON THE FIELDS COMPLICATED BY TECTONIC DISTURBANCES}

Andrey V. Stenkin',

andrey.stenkin@lukoil.com

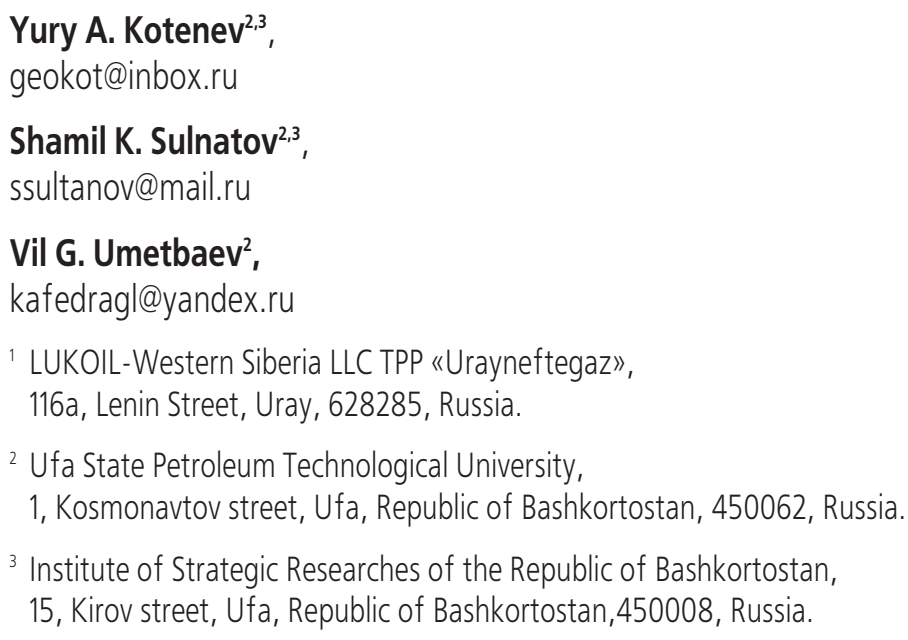

Relevance. A significant number of large oil fields are currently complicated by different tectonic dislocations. This article describes the influence of tectonic disorders on field development and production of oil reserves. The object of the study are the productive layers of the Jurassic deposits of the Shaim oil and gas bearing deposit, characterized by a high degree of heterogeneity and low values of filtration and capacitance properties, complicated by tectonic disturbances. Not achieving the plan of oil reserves production for such deposits requires detailed monitoring of the development, considering the main geological characteristics and subsequent regulation and improvement of the development system. The methodical approach to the improvement of the system of development of deposits complicated by tectonic disturbances includes critical analysis of primary geological, geophysical and fishing information, analysis of the main indicators of development characterizing the production of oil reserves

The main aim of the study is to determine the causes of uneven development of reserves by area and cut of productive strata, to stu$d y$ the influence of tectonic faults of various orders on the effectiveness of the used development system, including the flooding system of reservoirs.

The methods: geological and hydrodynamic modeling of exploration, geological and field analysis of exploration, analysis of the interpretation results of hydrodynamic studies of wells, comparative analysis of reservoir properties obtained by different research methods. The analysis of the efficiency of the development system was carried out using indirect methods of mathematical statistics, supported by the direct methods - tracer studies of wells.

The results. On the example of the Novomostovskoe oilfield the authors have selected hydrodynamically isolated areas with high values of mobile residual reserves limited by tectonic disturbances and proposed for them the geological and technical measures and technologies aimed at increasing the production of oil reserves. Based on the results of the studies the authors proposed a methodological justification for operational regulation and monitoring the exploration of the reservoir complicated by tectonic disturbances.

\section{Key words:}

Shaim oil and gas bearing deposits, tectonic disturbance, hydrodynamic interrelations between wells, development of oil reserves, Novomostovskoe oilfield.

\section{REFERENCES}

1. Salimov F.S., Lesnoy A.N., Kotenev Yu.A., Chudinova D.Yu. Osobennosti razrabotki zalezhey nefti oslozhnyonnykh tektonicheskimi narusheniyami [Designfeatures of seal oil complicated by tectonic disturbances]. Neftegazovoe delo, 2016, vol. 14, no. 1, pp. $42-48$.

2. Fazylova L.R., Kotenev Yu.A., Chudinova D.Yu., Valeev A.S., Dulkarnaev M.R. Osobennosti raspredelenieya fizicheskikh svoystv nefti v plastakh Vateganskogo neftyanogo mestorozhdeniya [Features of oil physical properties distribution in layers of Vatyegan oil field]. Sbornik nauchnykh trudov 43 Mezhdunarodnoy nauchno-tekhnicheskoy konferentsii molodykh uchenykh, aspirantov $\mathrm{i}$ studentov, posvyashchennoy 69-letiyu filiala UGNTU $v$ g. Oktyabrskom [Proc. of the 43 International Scientific and Technical Conference of Young Scientists, Post-Graduate Students and Stu- dents, dedicated to the $60^{\text {th }}$ anniversary of the USPTU branch in Oktyabrsky]. Oktyabrsky, 2016. Vol. 2, pp. 263-267.

3. Zatsepin 0.G., Stenkin A.V., Iks V.V., Kotenev Yu.A., Chudinova D.Yu. Problemy intensifikatsii dobychi nefti v nizkoproduktivnykh plastakh slozhnogo geologicheskogo stroeniya mestorozhdeniya Krasnoleninskogo svoda Zapadnoy Sibiri [Problem of intensification of oil production in low productivity reservoirs with complex Geology of the deposits of the Krasnoleninsk arch in Western Siberia]. Sbornik nauchnykh trudov 43 Mezhdunarodnoy nauchno-tekhnicheskoy konferentsii molodykh uchenykh, aspirantov i studentov, posvyashchennoy 69-letiyu filiala UGNTU v g. Oktyabrskom [Proc. of the 43 International Scientific and Technical Conference of Young Scientists, Post-Graduate Students and Students, dedicated to the $60^{\text {th }}$ anniversary of the USPTU branch in Oktyabrsky]. Oktyabrsky, 2016. Vol. 2, pp. 263-267. 
4. Valeev A.S., Dulkarnaev M.R., Kotenev Yu.A., Sultanov Sh.H., Brilliant L.S., Chudinova D.Yu. Metodicheskie osnovy planirovaniya i organizatsii intensivnykh sistem zavodneniya (na primere plastov Vateganskogo i Tevlinsko-Russkinskogo mestorozhdeniya) [Methodical bases of planning and organizing intensive floodingsystems (on example Vateganskoe and Tevlinsko-Russkinskoe fields)]. Exposition Oil \& Gas, 2016, no. 3 (49), pp. 38-44.

5. Sultanov Sh.H., Kotenev Yu.A., Andreev V.E., Stabinskas A.P., Grekhov I.V. Geoinformatsionnaya strategiya razrabotki mestorozhdeniya s trudnoizvlekaemymi zapasami nefti [Geoinformation strategy of developing fields with oil reserves difficult to recover]. Georesources, 2012, no. 3 (45), pp. 40-43.

6. Andreev V.E., Chudinova D.Yu., Chizhov A.P., Chibisov A.V. Optimizatsiya sistemy zavodneniya $\mathrm{v}$ terrigennykh i karbonatnykh kollektorakh [0ptimization of the waterflood system in terrigenous and carbonate reservoirs]. Problems of gathering, treatment and transportation of oil and oil products, 2016, no. 4 (106), pp. $42-53$

7. Amon E.0., Alexeev V.P., Glebov A.F., Savenko V.A., Fedorov Yu.N. Stratigrafiya i paleogeografiya mezozoysko-kaynozoyskogo osadochnogo chekhla Shaimskogo neftegazonosnogo rayona (Zapadnaya Sibir) [Stratigraphy and paleogeography of the Mesozoic-Cenozoic sedimentary cover of the Shaim oil and gas area (Western Siberia)]. Ekaterinburg, USMU Publ., 2010. 257 p.

8. Belousov S.L., Khuramshina O.A., Shabakova S.V., Chernova E.V. Paleofatsialny analiz otlozheniy tyumenskoy svity Krasnoleninskogo mestorozhdeniya [Paleofacies analysis of Tyumen Suite deposits of krasnoleninskoye field]. Scientific and Technical Gazette «ROSNEFT», 2014, no. 3, pp. 8-12.

9. Babin E.A., Belozerova M.A., Lyapin A.V. Strukturno-tektonicheskie i seysmodinamicheskie osobennosti otlozheniy tyumenskoy svity na primere mestorozhdeniya TPP "Urayneftegaz" [Structural-tectonic and seismodynamic features of the Tyumen Suite sediments on the example of the fields of TPP «Uraineftegaz»]. Puti realizatsii neftegazovogo $i$ rudnogo potentsialy KhMAO-Yugry. XVII nauchno-prakticheskaya konferentsiya [Khanty-Mansiisk, XVII scientific-practical conference. Ways of realizing the oil and gas and ore potential of the Khanty-Mansiysk Autonomous Okrug-Yugra]. Khanty-Mansiysk, 2013. pp. 152-159.

10. Kalgin V.P. Ispolzovanie dannykh seysmorazvedki dlya utochneniya geologicheskogo stroeniya tyumenskoy svity Krasnoleninskogo mestorozhdeniya [Use of seismic data to clarify the geological structure of the Tyumen Suite Krasnoleninsky field]. Science and Fuel and Energy Complex, 2012, no. 4, pp. 25-26.

11. Bykova I.O., Shuliko S.N., Goryachev A.A., Vilisov A.A., Koperchak A.V. Perspektivy Neftegazonosnosti otlozheniya verkhnetyumenskoy podsvity litsenzionnogo uchastka Surgutskiy 7 [Petroleum potential of the verkhntyumen subsuite of the license area of the Surgut 7]. Puti realizatsii neftegazovogo i rudnogo potentsiala KhMAO-Yugry. XIV nauchno-prakticheskaya konferentsiya [XIV scientific-practical conference. Ways of realizing the oil and gas and ore potential of the Khanty-Mansiysk $\mathrm{Au}^{-}$ tonomous Okrug-Yugra]. Khanty-Mansiisk, 2011, pp. 350-359.

12. Ivanov I.V. Metod uluchsheniya svyazannosti kollektorov tyumenskoy svity mestorozhdeniya Shaimskogo rayona pri postroenii geologicheskoy modeli na osnove pointervalnoy interpretatsii GIS [Method of improving the connectivity of reservoirs of Tyumen Suite of Shaimsky district fields in construction of a geological model based on interpretation of geophysical studies of wells]. Puti realizatsii neftegazovogo i rudnogo potentsiala KhMAO-Yugry. XIV nauchno-prakticheskaya konferentsiya [Khanty-Mansiysk, XIV scientific-practical conference. Ways of realizing the oil and gas and ore potential of the Khanty-Mansiysk Autonomous Okrug-Yugra]. Khanty-Mansiysk, 2011. pp. 230-237.

13. Kuzmin Yu.A., Ivanova N.A., Khaynovskaya Ya.A. Vliyanie epigeneticheskikh protsessov na filtratsionno-emkostnye svoystva porod-kollektorov tyumenskoy svity Shaimskogo NGR [Influence of epigenetic processes on filtration-capacitive properties of rocks-reservoirs of the Tyumen Suite of the Shaimsky oil and gas area]. Puti realizatsii neftegazovogo $i$ rudnogo potentsiala KhMAO-Yugry. XIV nauchno-prakticheskaya konferentsiya [Khanty-Mansiysk, XIV scientific-practical conference. Ways of realizing the oil and gas and ore potential of the Khanty-Mansiysk Autonomous Okrug-Yugra]. Khanty-Mansiysk, 2011. pp. 281-286.

14. Kuzmin Yu.A., Osipenko A.S. Monitoring geologicheskikh modeley zalezhey tyumenskoy svity v protsesse ikh dorazvedki i promyshlennosti expluatatsii (na primere plasta T1 Slavinskogo i Zapadno-Slavinskogo mestorozhdeniya) [Monitoring geological models of Tyumen Suite deposits at their further exploration and exploitation industry (on the example of T1 layer of Slavinsky and West Slavinsky deposits]. Puti realizatsii neftegazovogo i rudnogo potentsiala KhMAO-Yugry. XIV nauchno-prakticheskaya konferentsiya [Khanty-Mansiysk, XIV scientific-practical conference. Ways of realizing the oil and gas and ore potential of the Khanty-Mansiysk Autonomous Okrug-Yugra]. Khanty-Mansiysk, 2011. pp. 326-332.

15. Malshakov A.V., Efimov V.A., Kuzmin Yu.A., Borshchev V.V. Petrofizicheskaya model filtratsionno-emkostnykh svoystv produktivnykh otlozheniy tyumenskoy svity Shaimskogo rayona [Petrophysical model of reservoir properties of productive deposits of the Tyumen Suite of the Shaim district]. III nauchno-prakticheskaya konferentsiya. Puti realizatsii neftegazovogo i rudnogo potentsiala KhMAO [III scientific-practical conference. Ways of realizing the oil and gas and ore potential of the Khanty-Mansiysk Autonomous Okrug-Yugra]. Khanty-Mansiisk, 2000. pp. 323-333.

16. Alexeev V.P., Fedorov Yu.N., Gazaleev S.S., Russkiy V.I., Svechnikov L.I., Khakimov A.F. Istoriya formirovaniva otlozheniy tyumenskoy svity Shaimskogo neftegazonosnogo rayona [The history of formation of the deposits of the Tyumen Suite of the Shaim oil and gas district]. Geology of coal deposits, 2004, no. 14, pp. $130-139$.

17. Kerusov I.N., Strakhov P.N., Kerusova I.E., Nesterenko N.P., Miroshnichesnko D.E., Potryasov A.A., Skachek K.G., Mordvintsev M.V., Krylov D.N., Chernyaeva V.V. Metodicheskie aspekty issledovaniya produktivnykh otlozheniy tyumenskoy svity Yuzhno-Konitlorskogo mestorozhdeniya po materialam seysmicheskoy semki 3D [Methodical aspects of research of productive deposits of the Tyumen Suite of the Yuzhno-Konitlorsky field on materials of seismic survey 3D]. Puti realizatsii neftegazovogo i rudnogo potentsiala KhMAO-Yugry. VII nauchno-prakticheskaya konferentsiya [VII scientific-practical conference. Ways of realizing the oil and gas and ore potential of the Khanty-Mansiysk Autonomous 0krug-Yugra]. Khanty-Mansiysk, 2004. pp. 86-93.

18. Alekseev V.P., Gazaleev S.S., Svechnikov L.I. Stroenie i korrelyatsiya otlozheniy tyumenskoy svity [Structure and correlation of Tyumen suite]. Puti realizatsii neftegazovogo i rudnogo potentsiala KhMAO-Yugry. VIII nauchno-prakticheskaya konferentsiya [VIII scientific-practical conference. Ways of realizing the oil and gas and ore potential of the Khanty-Mansiysk Autonomous Okrug-Yugra]. Khanty-Mansiysk, 2005. pp. 346-352.

19. Bykova I.O., Shuliko S.N., Bykov A.V. Modelirovanie kolektorskikh svoystv tyumenskoy svity na primere mestorozhdeniy Yuganskogo Priobya [Structure and correlation of the deposits of the Tyumen Suite]. Puti realizatsii neftegazovogo i rudnogo potentsiala KhMAO-Yugry. IX nauchno-prakticheskaya konferentsiya [IX scientific-practical conference. Ways of realizing the oil and gas and ore potential of the Khanty-Mansiysk Autonomous Okrug-Yugra]. Khanty-Mansiysk, 2009. pp. 139-144.

20. Oshnyakov I.O. Utochnenie petrofizicheskoy modeli tyumenskoy svity Krasnoleninskogo mestorozhdeniya [Clarification of petrophysical model of the Tyumen Suite of the Krasnoleninsky De- 
posit]. Science and Fuel and Energy Complex, 2012, no. 4, pp. $43-44$.

21. Ji H.G., Ma H.S., Wang J.A., Zhang Y.H., Cao H. Mining disturbance effect and mining arrangements analysis of near-fault mining in high tectonic stress region. Safety Science, April 2012, vol. 50 , no. 4, pp. 645-651.

22. Pinxian W., Qianyu Li, Chun-Feng Li. Ch. 3. Tectonic Framework and Magmatism. Developments in Marine Geology, 2014, vol. 6, pp. 81-84.

23. Kontorovich V.A. The Meso-Cenozoic tectonics and petroleum potential of West Siberia. Russian Geology and Geophysics, April 2009, vol. 50, no. 4, pp. 350-352.

24. Nelson W.J., Denny F.B., Devera J.A., Follmer L.R., Masters J.M. Tertiary and Quaternary tectonic faulting in southernmost Illinois. Engineering Geology, July 1997, vol. 46, no. 3 (15) pp. 240-242.

25. Dayal A.M. Basin Structure, Tectonics, and Stratigraphy. Shale Gas, Exploration and Environmental and Economic Impacts, 2017, vol. 2, pp. 57-59.

26. Toker M., Celal Sengorc A.M., Demirel Schluter F.D., Demirbag E., Cukur D., Imren C., Niessen F. The structural elements and tectonics of the Lake Van basin (Eastern Anatolia) from multi-channel seismic reflection profiles. Journal of African Earth Sciences, May 2017, vol. 129, pp. 170-172.
27. Wei Y., Ran Q., Ran Li, Yuan J., Dong J. Determination of dynamic reserves of fractured horizontal wells in tight oil reservoirs by multi-region material balance method. Petroleum Exploration and Development, June 2016, vol. 43, no. 3, pp. 493-495.

28. Clancya S.A., Worralla F., Daviesb R.J., Gluyasa J.G. An assessment of the footprint and carrying capacity of oil and gas well sites: the implications for limiting hydrocarbon reserves. Science of the Total Environment, 2017, vol. 618, pp. 586-594.

29. Abdus Satter A., Iqbal G.M. Conventional and unconventional petroleum reserves - definitions and world outlook. Reservoir Engineering. The Fundamentals, Simulation, and Management of Conventional and Unconventional Recoveries, 2016, pp. 436-437.

30. Gupta N., Kleinhansb M.G., Addinkb E.A., Atkinsona P.M., Carlinga P.A. One-dimensional modeling of a recent Ganga avulsion: assessing the potential effect of tectonic subsidence on a large river. Geomorphology, 15 May 2014, vol. 213, pp. 25-29.

31. McCall G.J.H. Tectonics. Reference Module in Earth Systems and Environmental Sciences, 2013, vol. 227, pp. 320-322.

32. Somnath D., Boseb S., Dasc K. Tectonic evolution of the Eastern Ghats Belt. Precambrian Research, April 2013, vol. 227, pp. 250-252.

Received: 26 April 2018.

\section{Information about the authors}

Andrey V. Stenkin, deputy general director, LUKOIL-Western Siberia LLC TPP «Urayneftegaz» .

Yury A. Kotenev, Dr. Sc., professor, head of the department, Ufa State Petroleum Technological University; head of the laboratory, Institute of Strategic Researches of the Republic of Bashkortostan.

Shamil K. Sulnatov, Dr. Sc., associate professor, professor, Ufa State Petroleum Technological University; head of the laboratory, Institute of Strategic Researches of the Republic of Bashkortostan.

Vil G. Umetbaev, Dr. Sc., professor, Ufa State Petroleum Technological University. 